\title{
Low-cost patterning of thin film
}

*S Duby, B Ramsey, and D Harrison

School of Engineering and Design, Brunel University, Uxbridge, UK

\begin{abstract}
:
A novel route for the low-cost patterning of electrical thin films has been established. The process has been developed principally for the manufacture of thermocouples using high-speed reel-to-reel industrial techniques, but could be applied to the manufacture of a wide range of electronic devices including radio frequency identification (RFID) antennae, electrical interconnect, and passive electronic components.

The procedure exploits high-volume processes directly to print self-removing masking layers. The process offers substantial advantages over traditional thin-film patterning methods including faster, cheaper production runs. Raw material use and wastage are greatly reduced, affording environmental benefits.
\end{abstract}

Keywords: clean manufacturing, environmental, low cost, thermocouples, thin-film patterning.

\section{INTRODUCTION}

Vacuum deposition is a termused to describe several thin-film fabrication processes, including thermal evaporation and sputtering [1]. Industrially, thinfilm processes are applied widely for, among other things, the manufacture of organic light emitting diodes (LEDs) [2], the coating of architectural materials [3], and high-volume applications such as food packaging and decorative wrapping [4].

The advantages that thin-film manufacturing processes offer to the microelectronics industry are principally those associated with cost. Their commercial relevance has attracted considerable investment [5] and the processes are evolving and becoming increasingly affordable.

Conventional circuit-board manufacture is a polluting process, involving toxic processing agents including photo-sensitive chemicals, developers, and etching solutions. The process involves many steps and generates a large amount of waste. By comparison the thin-film processes discussed here offer significant environmental savings by minimizing wastage and the energy required for complete manufacture. This is in line with a number of recent European directives such as waste electrical and electronic equipment (WEEE) and restrictions of the use of certain hazardous substances (RoHS) which have added to the increasing pressure from consumers on manufacturers to extend their responsibility and adopt more environmentally friendly production methods.

Conductive thin films for electronic applications are produced usually using batch or single sample processes. It is thought that the principal barrier to their widespread application as part of a low-cost production line-type process is the lack of a simple, effective, and generic patterning technique. Currently, the most prevalent patterning process for thin films employs the same mechanisms as standard circuit board manufacture; photosensitized masking layers, developers, and etching agents [6]. Other processes for achieving patterned conductive films include the use of shadow-masking and masking oils and additive processes such as soft lithography and foil blocking.

Work has been carried out on the characterization of thin-film techniques. The processing conditions for the attainment of bulk material electrical and thermoelectric properties in thin films are well documented [7-9].

Low-cost manufacturing methods have been applied to the production of thermocouples. Qu et al. showed that 'economical' thermoelectric generators could be manufactured using methods such as foil lithography, electroplating, and wet chemical etching [10].

Thin-film thermocouples are used in numerous applications [11-14]. They have a number of advantages over their conventional bulk material counterparts; they are small and scalable [15] and have flexibility when it comes to their design and the materials that can be used in their manufacture [16].

Thin-film thermocouple sensors have been built that have microsecond response times to even very small temperature fluctuations [17]. The widespread interest and their diverse application arises because they can be used as both power generation systems and as high-performance temperature sensors. 


\section{METHOD}

Methods were investigated that allowed the direct printing of a masking ink on to a substrate which was then metallized. Depending on the nature of the ink, the required conditions would then be applied causing the mask to peel away from the substrate leaving behind a patterned thin film.

Various ink formulations were developed, the emphasis being on inks that would break their adhesive bond with the substrate with the application of certain external conditions.

The three mechanisms investigated to remove the masking ink layer were:

(a) heat and UV-triggered blowing agents;

(b) UV-triggered polymer degradation;

(c) self-peeling brittle inks (see Fig. 1).

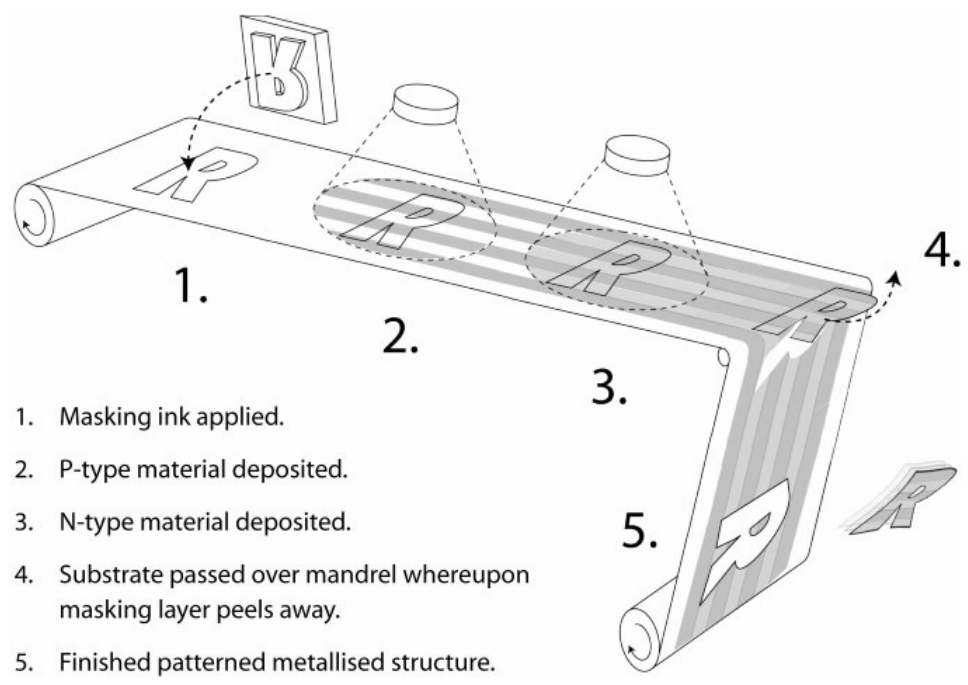

Fig. 1 The process of thin film patterning using a printable, peelable masking ink layer

The concept behind the use of blowing agents was that the triggered production of a quantity gas would increase the volume of the printed material and destructively alter the adhesive integrity between the substrate and the masking layer, allowing it to be removed easily.

UV-initiated polymer degradation is the process by which UV irradiation will break down the polymer chains of a resinous material effectively, reducing the average molecular weight and destroying its adhesive properties. Inks were developed using resins that would become brittle, once dried. To initiate removal of this ink, the completed metallized structure was passed over a mandrel, whereupon the brittle ink peeled itself away from the substrate, leaving behind a patterned thin film.

Various peeling-ink formulations were investigated using a variety of solvents including biodegradable n-methyl pyrrolidinone (NMP) and ethyl diglycol acetate (EGA).

It was shown that the addition of fillers and aggregates was beneficial to the peeling properties of the masking inks and various commonly used ink fillers were scrutinized, including Blanc Fixe (barium sulphate), china clay (kaolinite), Winnofil SP (calcium carbonate particulate coated with fatty acids) and Chinese Supa micronized talc (hydrated magnesium silicate) (see Table 1).

A test rig was built that allowed the application of a variable force acting perpendicularly to the substrate surface to be applied to a known surface area of printed ink. A measurement of the force needed to remove the ink from the substrate surface provided a means by which the adhesion of the different samples could be compared. 
Table 1 Peeling ink formulations and adhesion data

\begin{tabular}{|c|c|c|c|c|c|c|c|c|c|}
\hline Sample & Resin & $\%$ & Solvent & $\%$ & Filler & Density $(\mathrm{g} / \mathrm{cm} 3)$ & Formula & $\%$ & Adhesion $\left(\mathrm{N} / \mathrm{cm}_{2}\right)$ \\
\hline a & PMMA & 25 & BLO & 75 & - & - & - & - & 4.41 \\
\hline $\mathrm{b}$ & PMMA & 26 & NMP & 74 & - & - & - & - & 7.02 \\
\hline $\mathrm{c}$ & PMMA & 22 & NMP & 60 & China clay & 2.6 & $\mathrm{AlSiO}_{3}$ & 18 & 3.04 \\
\hline d & PMMA & 22 & NMP & 60 & Bicarb & 2.1 & $\mathrm{NaHCO}_{3}$ & 18 & 1.96 \\
\hline $\mathrm{e}$ & PMMA & 22 & NMP & 60 & Winnofil SP & 0.45 & $\mathrm{CaCO}_{3}$ & 18 & - \\
\hline $\mathrm{f}$ & PMMA & 22 & NMP & 60 & Blanc fixe & 4.5 & $\mathrm{BaSO}_{4}$ & 18 & - \\
\hline $\mathrm{g}$ & PMMA & 22 & NMP & 60 & Talc & 2.7 & $\mathrm{MgO} \mathrm{SiO}_{2} \mathrm{H}_{2} \mathrm{O}$ & 18 & - \\
\hline $\mathrm{h}$ & PMMA & 21 & EGA & 61 & China clay & 2.6 & $\mathrm{AlSiO}_{3}$ & 18 & 2.25 \\
\hline
\end{tabular}

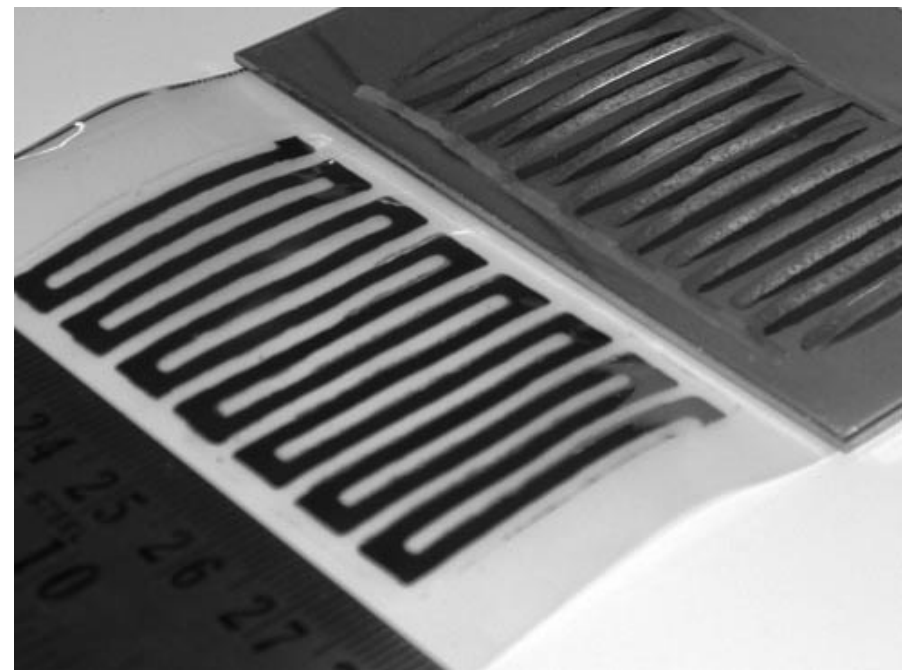

Fig. $2 \mathrm{Ni} / \mathrm{Fe}$ thermocluster structure and peeled PMMA masking ink

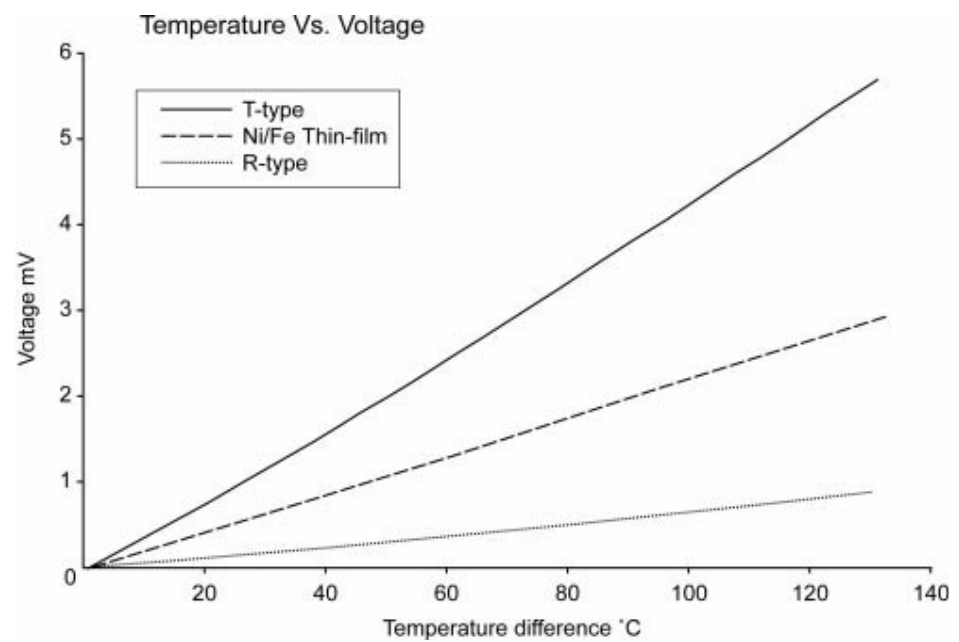

Fig. 3 Example of the thermoelectric reaction of an evaporated Ni/Fe thermocouple and two standard thermocouples 


\section{RESULTS}

Resin-based inks of polymethylmethacrylate (PMMA) were prepared that demonstrated exceptional brittleness under ambient conditions. The glass transition temperature of PMMA is approximately $105^{\circ} \mathrm{C}$ [18], below which the material will demonstrate glass-like brittleness.

It was shown that a solution of dissolved PMMA incorporating kaolinite (sample h) created an ink that could be screen-printed onto an untreated polyester substrate with suitable resolution.

Once the substrate was printed with the masking ink, two thermoelectrically active materials were evaporated on to the substrate, in an overlapping stripe configuration. Upon peeling, the masking layer was shown to be removed cleanly, leaving behind a series of thermocouples in a patterned thin-film thermocluster structure.

Film thicknesses of up to $500 \mathrm{~nm}$, approximately twice the thickness required to achieve conductivity of the bulk material [8] have been patterned in this manner. Passing the structures over a $1 \mathrm{~mm}$ radius edge resulted in no measurable change in the electrical resistance of the structure. Figure 2 shows an edge of an evaporated Ni film that was patterned using a PMMA-based peeling ink. It can be seen that there is no residue from the peeled ink left on the substrate. The edge definition and structural integrity of the masking ink was such that it peeled away in one piece, and the adhesion of the evaporated Ni film on the polyester substrate was such that the material was removed cleanly along the edge interface.

SEM analysis indicated a typical local edge roughness of approximately $3-5 \mu \mathrm{m}$. Traditional screenprinting techniques are quoted as typically being able to achieve a lateral resolution of $100 \mu \mathrm{m}$ [19] so this order of edge resolution was considered to be acceptable and suggests that the limitation lies with the screen-printing process and not the masking ink. This process has been applied successfully to the manufacture of complete thermocluster structures.

A test rig was built to characterize thermoelectrically the structures and was calibrated by testing standard thermocouples and comparing the resulting data to published data. Results were shown to correlate with theoretical data (within 5 per cent variance) [20].

Results demonstrated that thermocouples manufactured using the processes detailed above had a stable and repeatable reaction to temperature.

\section{CONCLUSIONS}

The use of brittle peeling inks was shown to be the most effective masking ink technology developed.

This work has shown the potential for the combination of vacuum deposition techniques and printable patterning processes to the manufacture of thermocouples.

Wider implications suggest the low-cost, clean, and environmentally sensitive manufacture of a wide variety of electrical circuitry and devices such as RFID antennae.

\section{References}

1 Kukla, R. Overview on modern vacuum web coating technology. Surf. Coatings Technol., 1996, 86-87 (2), $753-761$.

2 Kajii, H., Sakakibara, A., Okuya, A., Morimune, T., and Ohmori, Y. Organic transistors with indium tin oxide electrodes for driving organic light emitting diode. Thin Solid Films, 2005, 1-2(21), 415-419.

3 Szanyi, J. The origin of haze in CVD tin oxide thin films. Appl. Surf. Sci., 2002, 185 (3-4), 161-171.

4 Roy, R. Electrical and galvanomagnetic properties of nanocrystalline gallium nitride films. Thin Solid Films, 2005, 48 (1-2), 287295.

5 BCC report predicts optical thin-film boom - brief article - industry overview. Communs Today, February 4, 2003.

6 Deforest, W.Photoresist materials and processes, 1975 (McGraw-Hill, USA). 
7 Roy, R. Electrical and galvanomagnetic properties of nanocrystalline gallium nitride films. Thin Solid Films, 2005, 48 (1-2), 287295.

8 Marshall, R., Atlas, L., and Putner, T. The preparation and performance of thin-film thermocouples. J. Scient. Instrum., 1966, 43, 144-149. [CrossRef]

9 Pellicori, S. Choosing between thermal evaporation and sputter deposition. Coating Mater. News, 2000,10 (3).

10 Qu, W., Plötner, M., and Fischer, W. Microfabrication of thermoelectric generators on flexible foil substrates as a power source for autonomous microsystems. J. Micromech. and Microengng, 2001, 11, 146-152.

11 Zou, H., Rowe, D. M., and Min, G. Growth of p- and n-type bismuth telluride thin films by co-evaporation. J. Crystal Growth, 2000, 222, 82-87.

12 Castaño, E., Revelto, E., Martin, M. C., Garcia-Alonso, A., and Gracia, F. J. Metallic thin-film thermocouple for thermoelectric microgenerators. Sensors and Actuators A, 1997, 60, 65-67. [CrossRef]

13 Golan, G., Axelevitch, A., Sigalov, B., and Gorenstein, B. Integrated thin-film heater-thermocouple systems. Microelectronics Reliability, 2003, 43, 509-512. [CrossRef]

14 Lepicovsky, J., Bruckner, R. J., and Smith, F. A. Application of thin-film thermocouples to localised heat transfer measurements. AIAA Paper 95-2834 (NASA TM-107045), 1995.

15 II-Ho Kim (Bi, Sb) $2(\mathrm{Te}, \mathrm{Se})_{3}$-based thin film thermoelectric generators. Mater. Lett. 2000, 43, 221-224. [CrossRef]

16 Kreider, K., Ripple, D. C., and Dewitt, D. P. Calibration of thin-film thermocouples on silicon wafers. In Proceedings of the 7th International Symposium on Temperature, TEMPMEKO '99, Thermal Measurements in Industry and Science, June 1999, Delft, The Netherlands.

17 Heichal, Y., Chandra, S., and Bordatchev, S. A fastresponse thin film thermocouple to measure rapid surface temperature changes. Exp. Thermal and Fluid Sci., 2005, 30, 153-159. [CrossRef]

18 Soldera, A. Glass transition phenomena observed in stereoregular PMMAs using molecular modeling. Composites: Part $A$, 2005, 36, 521-530.

19 Lilliehorn, T. Fabrication of multilayer 2D ultrasonic transducer microarrays by green machining. J. Micromech. Microengng, 2004, 14, 702-709.

20 Guide to thermocouple and resistance thermometry, TC Limited, Issue 6.0, 2002.

*Corresponding author: School of Engineering and Design, Cleaner Electronics Research, Brunel University, Uxbridge, Middlesex UB8 3PH, UK. email: sam.duby@brunel.ac.uk 